\title{
Specification of Reliability Benchmarks for Offshore Wind Farms
}

\author{
D. McMillan \& G. W. Ault \\ Institute for Energy \& Environment \\ Department of Electronics and Electrical Engineering \\ University of Strathclyde \\ Royal College Building \\ 204 George Street \\ Glasgow, United Kingdom
}

Future deployment of offshore wind farms is perceived as a logical step in energy supply diversification by policy makers and large utilities. Capital costs are high and for this reason the investment decisions are focused on initial expenditure rather than operational costs, which are assumed to be small in comparison. Nevertheless, significant operational issues have arisen in existing offshore wind farms, highlighting the need for consideration of issues such as reliability and its impact on investment payback period. Hence, the key aim of the work is to establish a set of reliability thresholds which may provide important signals to prospective investors on how technical issues such as reliability and maintenance practice can impact on long-term investment decisions in offshore wind projects: aspects which have been largely ignored by wind farm investors until recently. The studies compare the effect of these aspects with more established key metrics such as capacity factor. Capacity factor is a key variable in wind farm design and extensive studies are employed to ensure yield at the sites will be high enough to merit investment. We argue that operational aspects are equally important in decision-making.

\section{INTRODUCTION}

At the beginning of 2008 offshore wind farms comprised only 587 Mega-Watts (MW) installed capacity globally (British Wind Energy Association, 2008), compared with 94,000MW total wind capacity, or just 0.6\% (Global Wind Energy Association, 2008). Yet, large-scale offshore deployment is seen as the future for the wind industry due to strong wind regimes and resultant energy yields offshore. Therefore, plans for expansion of offshore wind farms are ambitious, particularly in EU countries with high offshore wind potential such as Denmark, Germany, Spain and the UK.

Investment in offshore wind farms is encouraged through use of various indirect financial incentives provided by national governments, usually via increased revenue for the electricity generated as compared with traditional generators (e.g. thermal, nuclear). The capital expenditure (CAPEX) for an offshore installation is significantly larger than onshore, as well as increased operational expenditure (OPEX), including operation and maintenance (O\&M). This paper explores these issues via application of probabilistic models developed previously by the authors (McMillan \& Ault, 2008): based on a Markov Chain, time series model and Monte Carlo simulation (MCS).

\subsection{Offshore Wind Farm Characteristics}

Installation and operation of offshore wind farms is a challenging business. In particular, the operational nuances of a wind farm are quite different from the existing power stations such as coal, gas and nuclear. In the first instance, O\&M of wind turbines is coupled with weather conditions in a way which is not experienced by traditional power plants. Large distances to shore and access problems complicate engineering procedures which would be simple on land.

Furthermore, because of wind turbine (WT) economies of scale, future offshore wind farms are likely to comprise hundreds of units of perhaps 1$5 \mathrm{MW}$ each, spread over a large area. This is in contrast with traditional generating plant, typically comprising a single turbine hall with small numbers of electrical generators rated in 100s of MW. It is clear that new challenges in terms of O\&M will have to be faced, and that traditional approaches may not necessarily be effective and efficient in this new environment.

\subsection{Wind Turbine $O \& M$ and Reliability}

Academic and industrial interest in modelling of wind turbine O\&M has ballooned in recent years. Researchers at Energy Centre Netherlands and Delft 
University in the Netherlands were the first to build probabilistic models to estimate the cost of O\&M for offshore wind farms (Rademakers et al. 2003a, van Bussel \& Zaiijer, 2001). Previous to this, Sayas \& Allan (1996) had produced a seminal contribution using Markov Chains to estimate reliability of an onshore wind farm.

More recently the focus has shifted towards deciding a cost-optimal maintenance policy, which may include use of condition-based maintenance (CBM) or more traditional time-based maintenance (TBM). Work by Negra et al. (2007) focused on reliability of electrical components, while the contributions from Andrawus et al. (2007), Bhardawaj et al. (2007), McMillan \& Ault (2007a) and Phillips et al. (2005) have addressed the growing importance of wind turbine O\&M in different ways.

\section{MODELS FOR TECHNO-ECONOMIC ANALYSIS OF WIND FARMS}

The model elements which underpin the analysis in this paper are now discussed. These are: physical components and reliability, energy yield, maintenance policy and economic analysis.

\subsection{Physical Components: Markov Chain}

In previous work, a Markov Chain was identified as a suitable framework for modeling of WT component deterioration and failure processes. This is then embedded within a maintenance simulation solved by means of MCS resulting in a flexible and practical modelling solution. The main modelling issues for the Markov Chain representation are:

1. Number of WT components to include

2. Parameter estimation

The $1^{\text {st }}$ issue determines the number of system states and hence the complexity of the model. A combination of operational data and expert judgement was used to determine the four components - gearbox, generator, blade and electronics sub-assembly which constitute the model (McMillan \& Ault 2007b). The characteristics of these four components are summarised in Table 1, for the case of a $5 \mathrm{MW}$ offshore wind turbine. Other important operational detail in Table 1 includes component replacement cost and applicability of condition monitoring.

Table 1. 5MW Offshore wind turbine model summary.

\begin{tabular}{lccc}
\hline Component & $\begin{array}{c}\text { States } \\
\#\end{array}$ & $\begin{array}{c}\text { Replace Cost } \\
£\end{array}$ & $\begin{array}{c}\text { CBM Possible? } \\
\text { Y/N }\end{array}$ \\
\hline Gearbox & 3 & 402,000 & Yes \\
Generator & 3 & 201,000 & Yes \\
Rotor Blade & 3 & 166,000 & Yes \\
Electronic & 2 & 10,000 & No \\
\hline
\end{tabular}

Clearly in this case, the total number of system states can be calculated as 54 states ( 3 X 3 X 3 X 2): however the state space can be reduced considerably via use of simplifying assumptions. The most influential of these is that simultaneous failure events are not considered, which reduces the model to 28 states. This number is manageable for parameter estimation, which is achieved via a combination of reliability data, expert opinion and sensitivity analysis.

\subsection{Levels of Component Reliability}

Reliability data published in various forums has been utilised as part of this study. Estimates of wind turbine sub-component reliability derive either from large populations of operational wind turbines or from expert judgement. Studies by van Bussel \& Zaiijer (2001), Tavner et al. (2006, 2007), and Braam \& Rademakers (2004) show significant variation their estimates of annual component failure probability. Figure 1 illustrates the maximmum, minimmum and median values for each subcomponent failure probability, based on the research previously mentioned.

The key feature of these four sets of reliability figures is that the impact of reliability on offshore wind farm economics can be quantitatively evaluated based on a range of credible figures, since equivalent offshore data of this type is very scarce.

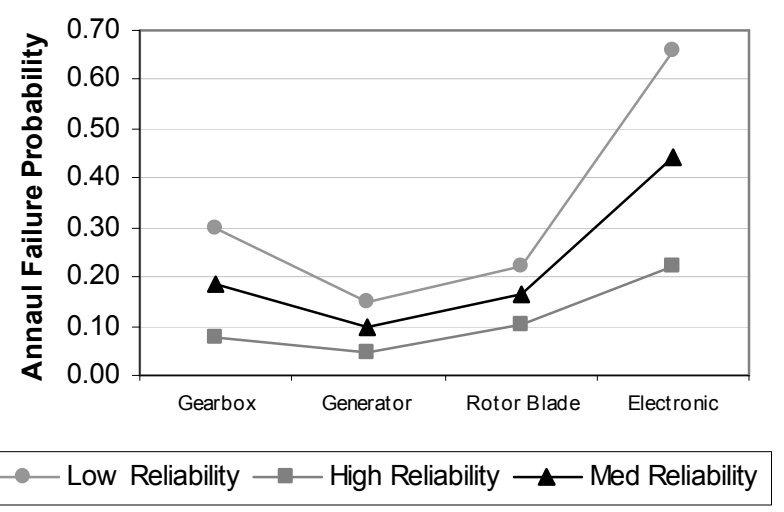

Figure 1. Spread of Wind Turbine Failure Probabilities.

\subsection{Energy Yield}

An autoregressive wind model has been developed which can be tailored for offshore wind profiles. This enables day to day correlations between wind speeds to be captured. The wind model is used in conjunction with a wind turbine power curve and economic metrics to determine the economic yield of the offshore wind turbine.

The economic yield also depends on the mechanisms in place to incentivise renewable-generated electricity, which varies depending on the energy policy of the individual country. For the purposes of this paper, the UK renewables obligation system is used as the example. This means that as well as gen- 
erating income per Mega-Watt hour (MWh) of electricity produced $\left(M P_{\text {elec }}\right)$, the wind turbine will accumulate renewable obligation certificates (ROCs) and is also able to get market price for these $\left(M P_{r o c}\right)$. Typical values for the market prices are illustrated in Table 2. A decision has not yet been reached on how the ROC system will change to accommodate offshore wind in the UK. An initial idea is that highrisk technologies such as offshore wind will be given a higher number of ROCs per MWh. For the purposes of this study it is assumed that offshore wind farms are allocated 1.5 ROCs per MWh.

Table 2. Summary of UK wind farm energy yield revenues.

\begin{tabular}{lcccc}
\hline Wind Farm & $\begin{array}{c}\text { ROC } \\
\text { \#/ MWh }\end{array}$ & $\begin{array}{c}\text { Elec MP } \\
£ / \text { MWh }\end{array}$ & $\begin{array}{c}\text { ROC MP } \\
£ / M W h\end{array}$ & $\begin{array}{c}\text { Revenue } \\
£ / \text { MWh }\end{array}$ \\
\hline Onshore & 1 & 36 & 40 & 76 \\
Offshore & 1.5 & 36 & 40 & 96 \\
\hline
\end{tabular}

\subsection{Operation and Maintenance Policy}

The two alternative maintenance philosophies adopted for offshore wind farms are TBM and CBM. TBM is conducted at a frequency of 1 action per year, on the basis of current industry practice and incurs a cost of approximately $£ 50,000$ per WT per annum. This is fairly consistent with a recent report by the UK government into the costs of offshore wind generation (Business, Enterprise \& Regulatory Reform, 2007) which estimates that OPEX will be in the range of $23 \%$ of CAPEX over the 20 year lifetime of a project: equivalent to $£ 57,000$ per WT per annum. CBM is applied as needed in response to the component condition and is worked out as a proportion of the annual TBM value: however the urgency of the maintenance action depends on the potential impact of the failure - in our case we consider the component replacement cost, shown in Table 1 as the economic impact.

The maintenance urgency, quantified as wait time, was determined by analysing the system to determine the cost-optimal time before maintenance action. Furthermore, maintenance actions are constrained due to wind speed safety limits, as shown in Table 3. These figures were obtained directly from a major utility involved in wind farm operations.

Table 3. Wind turbine maintenance constraints.

\begin{tabular}{cl}
\hline $\begin{array}{c}\text { Wind Speed } \\
\mathrm{m} / \mathrm{s}\end{array}$ & Access Restriction \\
\hline$>30$ & No site access \\
$>20$ & No climbing turbines \\
$>18$ & No opening roof doors \\
$>15$ & No work on nacelle roof \\
$>12$ & No access to hub \\
$>10$ & No lifting nacelle roof \\
$>7$ & No rotor blade removal \\
$>5$ & No climbing meteorology mast \\
\hline
\end{tabular}

Table 4. Wind turbine downtime per component failure.

\begin{tabular}{lcc}
\hline Component & $\begin{array}{c}\text { Downtime planned } \\
\text { Days }\end{array}$ & $\begin{array}{c}\text { Downtime unplanned } \\
\text { Days }\end{array}$ \\
\hline Gearbox & 1 & 42 \\
Generator & 1 & 32 \\
Rotor Blade & 1 & 42 \\
Electronic & 1 & 2 \\
\hline
\end{tabular}

Finally, some of the assumptions regarding downtime and maintenance are discussed. Planned maintenance actions are assumed to have a duration of one day if weather constraints are met (this applies for TBM or CBM). Unplanned outages adhere to the figures derived by McMillan \& Ault (2007a) via expert opinion. Typical downtime values for gearbox, generator, rotor blade and electronics failure are shown in Table 4. These figures include crane and component lead time, and are also weatherdependent. Repair costs for components are assumed to be $10 \%$ of the full component cost in Table 1.

\subsection{Use of Payback Period for Economic Ranking}

In order to competitively rank the economic implications of reliability and maintenance policy, the investment payback period method is used: this is the period of time the project takes to pay for itself. While there are clear simplifications in this method (e.g. interest rate is not considered), the purpose of the paper is to compare very similar investments, so in this sense it is fit for purpose.

\subsection{Capacity Factor of a Wind Farm}

The capacity factor (CF) of a wind farm is often a key indicator of its economic viability. It is the percentage of the equivalent full output if the wind farm ran at full capacity of all 8760 hours in the year. CF is dictated mainly by the wind characteristics but also by the rating of the wind turbine. A welldesigned onshore wind farm should have a CF of 30\% (Sayas \& Allan, 1996).

Offshore the CF may be much larger, perhaps as much as 43\% (Rademakers et al. 2003b). The motivation for including $\mathrm{CF}$ as a variable factor in the model is to compare the impact of a change in capacity factor with a change in reliability of the wind turbines. This is achieved by using two wind profiles, one equivalent to $28 \% \mathrm{CF}$ and the other equivalent to $38 \% \mathrm{CF}$.

\subsection{Program Operation}

The proposed combination of methods and input metrics were coded in FORTRAN 95. The three main building blocks of the code are the physical deterioration characterisation, yield calculation and maintenance model. A flowchart of the program operation has been included in Figure 2 . 


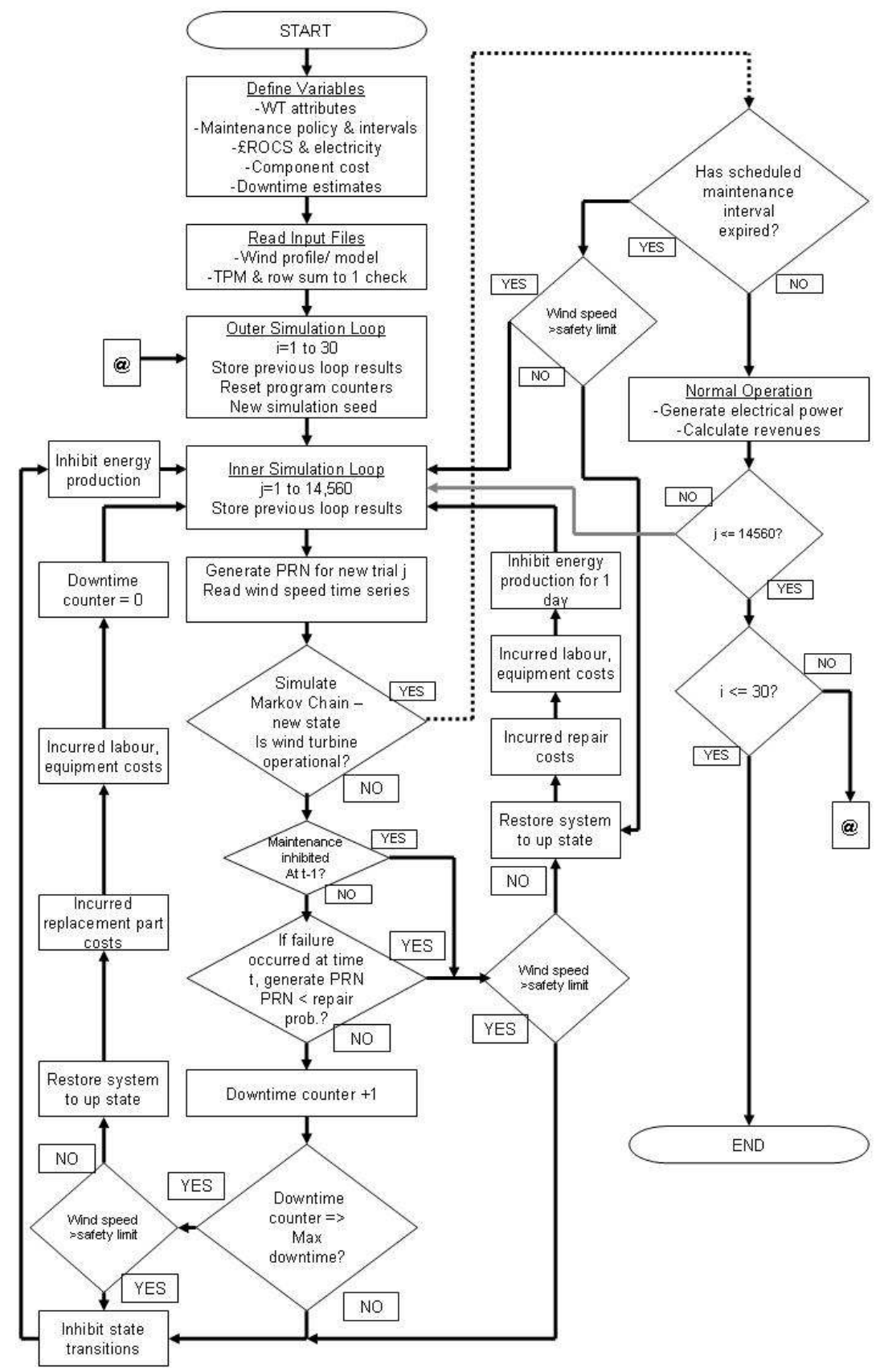

Figure 2. Program Flowchart.

\subsection{Example of Program Output}

An example of typical simulation output is shown in Table 5 - this is for the case of high reliability and low capacity factor (see sections 2.2 and 2.6 respectively).

The technical impact of $\mathrm{CBM}$ is to increase availability marginally, and decrease the failure rates of the key components. This necessitates more frequent maintenance actions (i.e. more maintenance cost) but the energy yield is boosted. For this particular scenario, TBM makes more economic sense than CBM.
Table 5. Example of MCS Output.

\begin{tabular}{|c|c|c|c|}
\hline \multicolumn{2}{|c|}{ Annual Metric } & TBM & CBM \\
\hline \multicolumn{2}{|c|}{ Availability \% } & 98.45 & 98.74 \\
\hline \multicolumn{2}{|c|}{ Yield MWh } & 12,387 & 12,437 \\
\hline \multicolumn{2}{|c|}{ Revenue $£$} & $1,076,905$ & $1,022,416$ \\
\hline \multicolumn{2}{|c|}{ Maintenance Freq. } & 1.0 & 2.6 \\
\hline \multirow{5}{*}{ 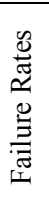 } & Overall Turbine & 0.466 & 0.324 \\
\hline & Gearbox & 0.074 & 0.022 \\
\hline & Generator & 0.043 & 0.018 \\
\hline & Rotor Blade & 0.112 & 0.056 \\
\hline & $\mathrm{E} \& \mathrm{E}$ & 0.238 & 0.229 \\
\hline \multicolumn{2}{|c|}{ Lost Energy MWh } & 168 & 69 \\
\hline
\end{tabular}




\section{OFFSHORE WIND FARM CASE STUDY}

The goal of this paper was to examine how reliability and O\&M practice impact on investment decisions for offshore wind farms. This is achieved by solving the described model for the different reliability levels in Figure 1 and applying both TBM and CBM.

Finally the impact of these two factors is compared with significant changes in $\mathrm{CF}$ to quantify the importance of operational issues relative to more established metrics.

\subsection{Base Case}

For the initial study a wind farm comprising $5 \mathrm{MW}$ units with a fairly low CF of $28 \%$ is examined. The assumption in Figure 3 regarding offshore ROCs is held. Capital costs of $£ 1,000,000$ per MW installed capacity are assumed.

Figure 3 shows the payback period for the base case, and its sensitivity to reliability level and maintenance policy.

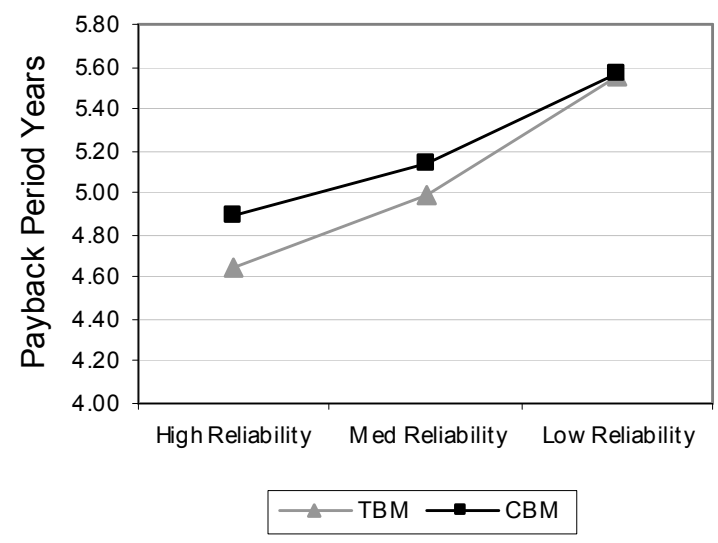

Figure 3. Impact of reliability and maintenance policy on payback period

Figure 3 shows that there is significant coupling between the reliability of the wind farm and the investment payback period. Taking the extreme high and low reliability cases for TBM, the difference is 0.92 years.

Examination of the impact of maintenance policy reveals that $\mathrm{CBM}$ is less cost-effective that TBM, however the gap reduces as the system becomes less reliable. Previous work by the authors (McMillan \& Ault, 2007a) had indicated a clear economic case for CBM relative to TBM, however the reliability in that case was lower than the figures evaluated in this paper (i.e. the line would extend to the right of Figure 3). This suggests that there is a reliability 'crossover point' at which it makes economic sense to switch from TBM to $\mathrm{CBM}$ for maintenance of offshore wind farms.

\subsection{Comparison of Reliability, $O \& M$ and $C F$}

The main result comprises the same analysis in the base case, with the addition of an increase in CF from $28 \%$ to $38 \%$. The result in Figure 4 enables the comparison suggested between reliability, maintenance and $\mathrm{CF}$.

The first point of interest is that for the case of TBM and with high reliability, the difference in payback period caused if $\mathrm{CF}$ is changed from $28 \%$ to $38 \%$ is -1.21 years. However there seems to be an inter-dependency between $\mathrm{CF}$ and reliability because as the wind farm gets less reliable, the difference caused by the $+10 \% \mathrm{CF}$ increases from -1.21 years to -1.35 and finally to -1.64 in the case of low reliability.

If the effect of reliability alone is considered, for the $28 \%$ CF case the payback period is increased by 0.35 years and 0.92 years respectively as the system gets less reliable (upper trace, same as Figure 3). The same figures for 38\% CF case are +0.21 years and +0.49 years, so it seems that the system is less sensitive to unreliability impacts if the wind profile is stronger, possibly owing to component replacement costs becoming less dominant in comparison with energy yield.

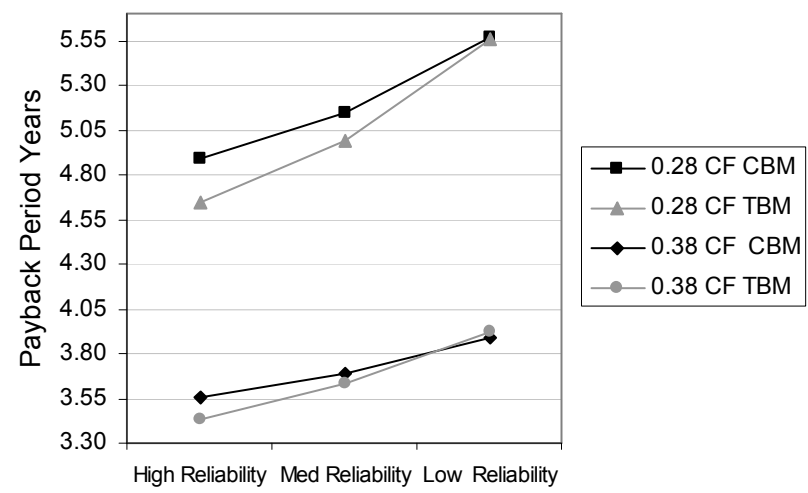

Figure 4. Comparison of reliability, O\&M and CF influence on payback period.

This is observed intuitively by noticing the gradient of the trace is greater in the $28 \%$ CF case.

In order to visualise these impacts in a relative manner, Figure 5 is introduced. The scale is normalised to the greatest impact (CF impact at low reliability $=-1.64$ years). Clearly, an increase in $\mathrm{CF}$ will decrease the payback period, while lowering reliability will increase it, however the main interest here is magnitude of variable coupling. It is clear from Figure 5 that, while $\mathrm{CF}$ is the dominant influence on payback period, reliability is also highly significant. For the case of low reliability at $28 \% \mathrm{CF}$, reliability has almost $60 \%$ of the impact of a $+10 \%$ increase in $\mathrm{CF}$, which is a very significant conclusion. 


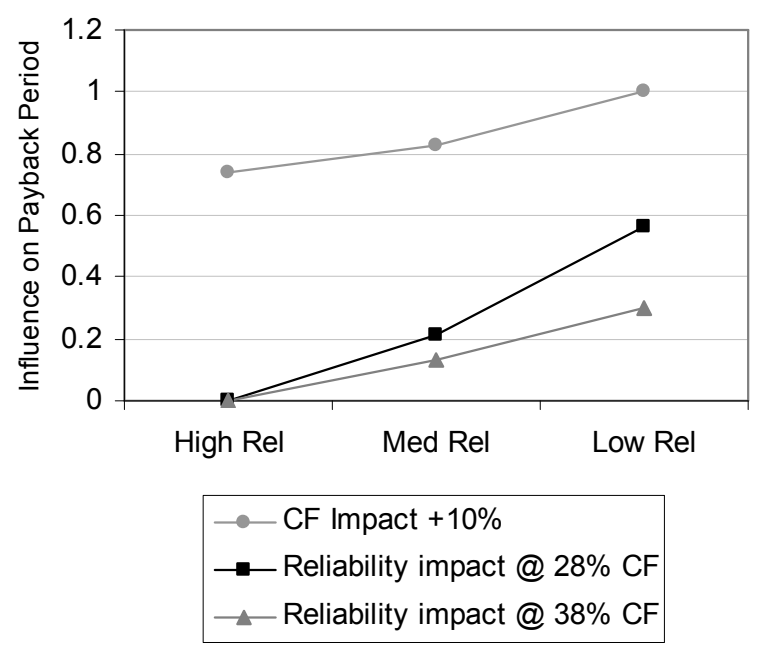

Figure 5. Relative comparison of influence of reliability and capacity factor on payback period.

\section{CONCLUSIONS}

This paper set out to investigate the relationship between investment payback periods of offshore wind farms and operational factors such as reliability and O\&M. Additionally, it was suggested that a comparison with capacity factor would help contextualise the importance of operational issues.

No 'reliability threshold' was discovered as such, since it was clear that all levels of reliability evaluated were acceptable from the viewpoint of paying back the investment in 6 years at the most, even with a relatively low capacity factor of $28 \%$. This is probably due to the increased level of revenue generated as a result of reforms to the UK renewable obligations system, which may make offshore wind farms an attractive investment for utilities. Elsewhere, feed-in tariff systems will produce a similar effect of the subsidy is set at an adequate level. It should be noted, however that the assumption of $£ 1 \mathrm{M}$ per MW installed offshore may be conservative and the same may be said of the assumption of $£ 50,000$ per turbine per year in the case of TBM, since these costs are not yet well understood.

The most significant result is Figure 5 which clearly indicates that the reliability of individual wind turbine components can have an appreciable effect on payback period for the wind farm. While this shows reliability to be less significant than capacity factor, in some cases the influence is as much as $\sim 60 \%$ of CF influence. This seems to back up the theory that reliability will be an important issue for future offshore wind farms, and perhaps be considered as significant as estimating the wind regime at a potential site.

Finally, in most of the cases a time based maintenance policy was the most cost-effective, however Figure 4 shows that a crossover point will ex- ist at which condition-based maintenance becomes the most cost effective option. Figure 4 also illustrates the fact that if the system is very reliable, the economic argument for CBM no longer exists. Nevertheless, industry opinion seems to be that meeting high reliability targets will be a challenge for offshore wind turbines owing to environmental conditions, meaning that the crossover point will be reached and thus enabling CBM.

\section{Acknowledgements}

The authors would like to thank the PROSEN project (www.prosen.org.uk) and EPSRC for funding this research.

\section{REFERENCES}

Andrawus, J., Watson, M., \& Kishk, M. 2007. Wind Turbine Maintenance Optimisation: principles of quantitative maintenance optimisation. Wind Engineering, v31, n3, p101-110

Business, Enterprise \& Regulatory Reform. 2007. Study of the Costs of Offshore Wind Generation. http:/www.berr.gov.uk/files/file38125.pdf

Bhardawaj, U.R., Speck, J.B. \& Ablitt, C.J. 2007. A Practical Approach to Risk Based Assessment and Maintenance Optimisation of Offshore Wind Farms. Proceedings of $26^{\text {th }}$ International Conference on Offshore Mechanics and Arctic Engineering, San Diego, USA

Braam, H. \& Rademakers, L.W.M.M. 2004. Models to Analyse Operation and Maintenance Aspects of Offshore Wind Farms. ECN Report, no longer available online.

British Wind Energy Association. 2008. Offshore Wind Worldwide.

http://www.bwea.com/offshore/worldwide.html

Global Wind Energy Council. 2008. Continuing boom in wind energy - $20 \mathrm{GW}$ of new capacity in 2007 URL: http://www.gwec.net/index.php? id $=30 \&$ no cache $=1 \&$ tx ttnews $[t \mathrm{t}$ news $]=121 \&$ tx ttnews $[$ backPid $]=4 \& c H a s h=f 9 b 4 a f 1 c d 0$

McMillan, D \& Ault, G.W. 2008. Condition Monitoring for Onshore Wind Turbines: Sensitivity to Operational Parameters. IET Renewable Power Generation, v, n, pp?-?

McMillan, D. \& Ault, G.W. 2007a. Quantification of Condition Monitoring Benefit for Offshore Wind Turbines. Wind Engineering, v 31, n 4, pp 267-285

McMillan, D. \& Ault, G.W. 2007b. Towards Quantification of Condition Monitoring Benefit for Wind Turbine Generators, European Wind Energy Conference, Milan

Negra, N.B., Holestrom, O., Bak-Jensen, B. \& Sorensen, P. 2007. Aspects of Relevance in Offshore Wind Farm Reliability Assessment. IEEE Transactions on Energy Conversion, 22, (1), pp. 159-166

Phillips, J.L., Morgan, C.A., \& Jacquemin, J. 2005. Understanding uncertainties in energy production estimates for offshore wind farms, Garrad Hassan and Partners 
Rademakers, L.W.M.M., Braam, H. \& Verbruggen,T.W. 2003a. R\&D needs for O\&M of wind turbines. ECN paper.

http://www.ecn.nl/docs/library/report/2003/rx03045.pdf

Rademakers, L.W.M.M., Braam, H., Zaaijer, M.B. \& van Bussel, G.J.W. 2003b.Assessment and Optimisation of Operation and Maintenance of Offshore Wind Turbines. European Wind Energy Conference, Madrid.

Sayas, F.C. \& Allan, R.N. 1996. Generation availability assessment of wind farms, IEE Proceedings- Generation, Transmission, \& Distribution. 143, (5), pp. 507-518

Tavner, P.J., Xiang, J. \& Spinato, F. 2007. Reliability Analysis for Wind Turbines, Wind Energy, 10, (1), pp. 1-18

Tavner, P.J., van Bussel, G.J.W. \& Spinato, F. 2006. Machine and Converter Reliabilities in Wind Turbines, Power Electronics Machines \& Drives Conference. pp. 127-130

van Bussel, G.J.W. \& Zaaijer, M.B. 2001. Reliability, Availability and Maintenance aspects of large-scale offshore wind farms. Proceedings of MAREC, Newcastle 